\title{
Effectiveness of Endovenous Radiofrequency Ablation for Elderly Patients with Varicose Veins of Lower Extremities
}

\author{
Kiyoshi Tamura, MD, PhD, Toshiyuki Maruyama, MD, and Syogo Sakurai, MD
}

Objective: The purpose of this study was to evaluate safety and effectiveness of endovenous radiofrequency ablation (RFA) for elderly patients.

Materials and Methods: We enrolled 140 patients (194 limbs) who underwent RFA for varicose veins of lower extremities. Patients were divided into two groups; elderly patients (more than 75 years old, E-group, $\mathrm{n=36}$ ) and young patients (under 75 years old, Y-group, $n=104$ ), and perioperative data were analyzed and compared between two groups.

Results: In E-group, there were more than patients with hypertension, ischemic heart disease, malignant tumor, and cerebrovascular disease. A partial recanalization was observed in only one limb (0.6\%) in Y-group. Endovenous heat induced thrombosis (EHIT) was identified four limbs (2.8\%) in Y-group and two limbs (4.1\%) in E-group. All EHITs were class 1 by Kabnick classification, and they disappeared within one month after interventions, without antithrombotic therapy. No other major complications were observed. There were no significantly differences for preoperative mean venous clinical severity scores (VCSS) $(\mathrm{Y}: \mathrm{E}=4.84: 4.47)$ and postoperative VCSS $(\mathrm{Y}: \mathrm{E}=1.16: 1.19$, $0.35: 0.58,0.15: 0.06,0.05: 0.06$ at $1,3,6,12$ months after) in both groups.

Conclusion: RFA for elderly patients is a safe and effective strategy for varicose veins of lower extremities.

Keywords: varicose vein, radiofrequency ablation, elderly patient, venous clinical severity score

Department of Cardiovascular Surgery, Soka Municipal Hospital, Soka, Saitama, Japan

Received: January 7, 2019; Accepted: March 11, 2019 Corresponding author: Kiyoshi Tamura, MD, PhD. Department of Cardiovascular Surgery, Soka Municipal Hospital, 2-21-1 Soka, Soka, Saitama 340-8560, Japan

Tel: +81-48-946-2200, Fax: +81-48-946-2211

E-mail: tamuratsrg@yahoo.co.jp

(cc) BY-NC-SA (02019 The Editorial Committee of Annals of Vascular Diseases. This article is distributed under the terms of the Creative Commons Attribution License, which permits use, distribution, and reproduction in any medium, provided the credit of the original work, a link to the license, and indication of any change are properly given, and the original work is not used for commercial purposes. Remixed or transformed contributions must be distributed under the same license as the original.

\section{Introduction}

Varicose veins (VVs) of lower extremities are common vascular diseases. In Japan, there are more than thirty thousand patients who are treated for VVs per year. ${ }^{1,2)}$ In these cases, patients over 70 years old were about $30 \%$, and have increased every year. ${ }^{1)}$

Previously, the treatment of VVs has been surgery involving high ligation and stripping of the saphenous veins. ${ }^{3)}$ However, endovenous techniques, such as endovenous laser ablation (EVLA) and endovenous radiofrequency ablation (RFA), have recently been introduced.2) In particular, RFA is a relatively new treatment and is a minimally invasive intervention that has become one of common alternatives in Japan.

Though RFA is associated with fewer postoperative complications, ${ }^{4)}$ there are few evidences for RFA of advanced age patients. The aim of this study was to investigate mid-term result of RFA for VVs in elderly patients.

\section{Materials and Methods}

This retrospective study was approved by the institutional review board, and a written informed consent was obtained from all of the patients.

A total of 173 patients underwent surgical interventions for VVs in our institution between May 2015 and October 2017. We defined VVs as varicose veins caused by saphenous reflux. All patients had visited outpatient clinics for twelve months. In these cases, patients with preoperative vein diameter at sapheno-femoral junction of less than $10 \mathrm{~mm}$ were selected for RFA. When the diameter was more than $10 \mathrm{~mm}$, stripping of saphenous vein was undertaken. The patients treated with stripping were excluded in this study. Therefore, 194 limbs in 140 patients were enrolled in our study.

The 140 enrolled patients were divided into two groups; elderly patients (more than 75 years old, E-group, $n=36$, leg $=49$ ) and young patients (under 75 years old, Y-group, $\mathrm{n}=104$, leg $=145$ ), and perioperative data were analyzed and compared between two groups. The reason we chose 
elderly as 75 years and older is because this is the definition of elderly in Japan's health care system.

In our institution, all patients with varicose veins of the lower extremities underwent both ultrasonography and magnetic resonance venography (MRV) to detect deep vein thrombosis (DVT). Because MRV could detect DVT in middle femoral veins that might be difficult to detect using ultrasonography, ${ }^{5)}$ we performed MRV as a routine examination.

RFA was performed using Closure Fast ${ }^{\mathrm{TM}}$ catheters (Covidien, Mansfield, MA, USA). As RFA procedure, the patient's leg was prepped with disinfectant solution and draped in a sterile fashion. With ultrasound guidance, the vein was cannulated. The RFA catheter was accessed with a $7 \mathrm{Fr}$ sheath, and RFA catheter was sent through it to the sapheno-femoral junction. The radiofrequency energy was delivered to $120^{\circ} \mathrm{C}$. A venous segment $7 \mathrm{~cm}$ in length was treated in 20-s cycles. In all cases, the anesthesia methods were performed with femoral nerve block and tumescent local anesthesia.

To assess endovenous heat induced thrombosis (EHIT) and the occlusion rate of the treated veins, duplex ultrasound scannings were performed at 1 day, 1 week, 1 month, 3 months, 6 months, and 1 year.

The following characteristics were analyzed at the time of diagnosis: demographic features, predisposing family history and past personal history, clinical features, treatment, and outcome. Preoperative examinations included echocardiographic studies, radiologic images, and results of routine laboratory tests (including hematological value, lipid parameter, liver and renal function, and inflammatory parameters).

There were preoperative patients' characteristics in Table 1. Ninety-two patients $(65.7 \%)$ were female. The mean age was $68.3 \pm 9.5$ years (35-85 years). A total of 107 patients $(78.8 \%)$ and 155 limbs $(79.9 \%)$ had VVs of the great saphenous veins, and 33 patients $(21.2 \%)$ and 39 limbs (20.1\%) had short saphenous veins. VVs were evaluated according to the Clinical Etiology Anatomy Pathophysiology (CEAP) classification before RFA: 123 limbs $(87.9 \%)$ were graded as C2 and C3.

Diabetes mellitus (DM) was defined as the recent use

Table 1 Demographic preoperative characteristics of all patients

\begin{tabular}{|c|c|c|c|}
\hline & Y-group $(n=104)$ & E-group $(n=36)$ & $p$ value \\
\hline Age (year) & $64.6 \pm 8.5(35-74)$ & $78.9 \pm 2.7(75-85)$ & $<0.001$ \\
\hline Sex (female) & $69(66.3 \%)$ & $23(63.9 \%)$ & 0.791 \\
\hline \multicolumn{4}{|l|}{ Prevalence } \\
\hline Hypertension & $28(26.9 \%)$ & $23(63.9 \%)$ & $<0.001$ \\
\hline Dyslipidemia & $58(55.8 \%)$ & $22(61.1 \%)$ & 0.580 \\
\hline $\mathrm{DM}$ & $17(16.3 \%)$ & $9(25.0 \%)$ & 0.253 \\
\hline CKD & $0(0.0 \%)$ & $0(0.0 \%)$ & \\
\hline COPD & $9(8.7 \%)$ & $7(19.4 \%)$ & 0.081 \\
\hline Ischemic heart disease & $2(1.9 \%)$ & $11(30.6 \%)$ & $<0.001$ \\
\hline Malignant tumor & $7(6.7 \%)$ & $7(19.4 \%)$ & 0.029 \\
\hline Cerebrovascular disease & $0(0.0 \%)$ & $3(8.3 \%)$ & 0.003 \\
\hline Bone disorder & $8(7.7 \%)$ & $6(16.7 \%)$ & 0.124 \\
\hline Digestive disease & $10(9.6 \%)$ & $1(2.8 \%)$ & 0.191 \\
\hline Blood disorder & $3(2.9 \%)$ & $0(0.0 \%)$ & 0.306 \\
\hline Genital organ disease & $12(11.5 \%)$ & $2(5.6 \%)$ & 0.282 \\
\hline Thyroid disorder & $4(3.8 \%)$ & $3(8.3 \%)$ & 0.290 \\
\hline Ejection fraction (\%) & $69.1 \pm 4.7$ & $69.7 \pm 6.2$ & 0.547 \\
\hline Length of varicose veins (year) & $12.1 \pm 12.4(1-49)$ & $12.1 \pm 13.6(1-48)$ & 0.974 \\
\hline Varix of GSV & $80(76.9 \%)$ & $27(75.0 \%)$ & 0.816 \\
\hline (number of limbs) & $(119,82.1 \%)$ & $(36,73.5 \%)$ & 0.167 \\
\hline Varix of SSV & $24(23.1 \%)$ & $9(25.0 \%)$ & 0.816 \\
\hline (number of limbs) & $(26,17.9 \%)$ & $(13,26.5 \%)$ & 0.158 \\
\hline \multicolumn{4}{|l|}{ CEAP classification } \\
\hline $\mathrm{C} 2$ & $54(51.9 \%)$ & $16(44.4 \%)$ & 0.433 \\
\hline $\mathrm{C} 3$ & $37(35.6 \%)$ & $16(44.4 \%)$ & 0.348 \\
\hline $\mathrm{C} 4 \mathrm{a}$ & $10(9.6 \%)$ & $3(8.3 \%)$ & 0.821 \\
\hline $\mathrm{C} 4 \mathrm{~b}$ & $3(2.9 \%)$ & $1(2.8 \%)$ & 0.974 \\
\hline
\end{tabular}

DM: diabetes mellitus; CKD: chronic kidney disease; COPD: chronic obstructive pulmonary disease; GSV: great saphenous vein; SSV: small saphenous vein; CEAP: clinical etiology anatomy pathophysiology 
of anti-diabetic drugs, fasting blood glucose $>126 \mathrm{mg} / \mathrm{dl}$, and/or hemoglobin $\mathrm{A}_{1 \mathrm{c}}>6.5 \%$. Chronic kidney disease $(\mathrm{CKD})$ was defined as estimated glomerular filtration rate (eGFR) $<30 \mathrm{ml} / \mathrm{min} / 1.73 \mathrm{~m}^{2}$.

Continuous variables are expressed as medians \pm SD with ranges when appropriate. Categorical variables are expressed as numbers (\%) and were compared using the Student's t-test for continuous variables. Examinations of parametric data were used with contingency tables, with Fisher's exact test, as appropriate. Differences were considered significant at $p<0.05$. Stat View for Windows version 6.0 (SAS Institute Inc., Cary, NC, USA) software program was used for all calculations.

\section{Results}

In E-group, there were more patients with hypertension $(\mathrm{Y}: \mathrm{E}=26.9: 63.9 \%, \mathrm{p}<0.001)$, ischemic heart disease $(\mathrm{Y}: \mathrm{E}=1.9: 30.6 \%, \mathrm{p}<0.001)$, malignant tumor $(\mathrm{Y}: \mathrm{E}=6.7: 19.4 \%, \mathrm{p}=0.029)$, and cerebrovascular disease $(\mathrm{Y}: \mathrm{E}=0.0: 8.3 \%, \mathrm{p}=0.003)$, compared with $\mathrm{Y}$ group (Table 1). There was no significant difference in the length of VVs between both groups. There were also no significant differences in CEAP classifications between both groups.

Major complications after RFA are shown in Table 2. In one limb $(0.6 \%)$, a partial recanalization was observed in Y-group. Therefore, the occlusion rate of the treated veins was $99.4 \%$. The cause of recurrent varicose vein was residual tributary.

EHITs were identified two limbs $(4.1 \%)$ in E-group and four limbs $(2.8 \%)$ in Y-group (Table 2, $\mathrm{p}=0.665)$. All EHITs were class 1 by Kabnick classification, ${ }^{6}$ ) and they naturally disappeared within one month after interventions, without antithrombotic therapy. There was no other major complication such as DVT and nerve injury in any of the patients.

There were minor complications after RFA in Table 3. There were more patients with edema in E-group than Y-group ( $\mathrm{Y}: \mathrm{E}=1.0: 13.9 \%, \mathrm{p}<0.001)$. Other minor complications, such as pain, numbness, induration, muscle clamping, localized hot flashes, dullness, and red flare, were equally observed after RFA in both groups. As a result, procedure pain $(\mathrm{Y}: \mathrm{E}=19.2: 27.8 \%, \mathrm{p}=0.285)$ and procedure bruising $(\mathrm{Y}: \mathrm{E}=19.2: 11.1 \%, \mathrm{p}=0.268)$ were evenly noted in both groups.

There were no significant differences for preoperative mean venous clinical severity scores (VCSS) $\quad(\mathrm{Y}: \mathrm{E}=4.84: 4.47)$ and postoperative VCSS $(\mathrm{Y}: \mathrm{E}=1.16: 1.19,0.35: 0.58,0.15: 0.06,0.05: 0.06$ at 1 , $3,6,12$ months after) in both groups (Table 4). Between both groups, each postoperative VCSSs improved from preoperative VCSS (data not shown, $\mathrm{p}<0.0001$ ).
Table 2 Postoperative major complication after endovenous radiofrequency ablation

\begin{tabular}{lccc}
\hline & $\begin{array}{c}\text { Y-group } \\
(\text { leg=145) }\end{array}$ & $\begin{array}{c}\text { E-group } \\
(\text { leg=49) }\end{array}$ & p value \\
\hline EHIT & $4(2.8 \%)$ & $2(4.1 \%)$ & 0.665 \\
Recanalization of vein & $1(0.6 \%)$ & $0(0.0 \%)$ & 0.558 \\
\hline
\end{tabular}

EHIT: endovenous heat induced thrombosis

Table 3 Postoperative minor complication after endovenous radiofrequency ablation

\begin{tabular}{lccr}
\hline & $\begin{array}{c}\text { Y-group } \\
(\mathrm{n}=104)\end{array}$ & $\begin{array}{c}\text { E-group } \\
(\mathrm{n}=36)\end{array}$ & p value \\
\hline Pain & $24(23.1 \%)$ & $11(30.6 \%)$ & 0.173 \\
Numbness & $15(14.4 \%)$ & $1(2.8 \%)$ & 0.135 \\
Induration & $8(7.7 \%)$ & $0(0.0 \%)$ & 0.143 \\
Muscle cramping & $5(4.8 \%)$ & $4(11.1 \%)$ & 0.421 \\
Localized hot flashes & $3(2.9 \%)$ & $1(2.8 \%)$ & 0.974 \\
Dullness & $2(1.9 \%)$ & $1(2.8 \%)$ & 0.674 \\
Red flare & $1(1.0 \%)$ & $0(0.0 \%)$ & 0.558 \\
Edema & $1(1.0 \%)$ & $5(13.9 \%)$ & $<0.001$ \\
Procedure pain & $20(19.2 \%)$ & $10(27.8 \%)$ & 0.285 \\
Procedure bruising & $20(19.2 \%)$ & $4(11.1 \%)$ & 0.268 \\
\hline
\end{tabular}

Table 4 Perioperative changes in venous clinical severity score

\begin{tabular}{lccc}
\hline & $\begin{array}{c}\text { Y-group } \\
(\mathrm{n}=104)\end{array}$ & $\begin{array}{c}\text { E-group } \\
(\mathrm{n}=36)\end{array}$ & p value \\
\hline Pre-operation & $4.84 \pm 1.12$ & $4.47 \pm 0.85$ & 0.076 \\
After 1 month & $1.16 \pm 1.29$ & $1.19 \pm 1.31$ & 0.901 \\
After 3 months & $0.35 \pm 0.81$ & $0.58 \pm 0.94$ & 0.148 \\
After 6 months & $0.15 \pm 0.59$ & $0.06 \pm 0.33$ & 0.343 \\
After 12 months & $0.05 \pm 0.29$ & $0.06 \pm 0.33$ & 0.899 \\
\hline
\end{tabular}

\section{Discussion}

Compared with conventional surgery like stripping of the saphenous veins, the effectiveness and safety of endovascular treatment of VVs have been well demonstrated in a number of studies. Endovenous techniques have been recommended for the treatment of VVs by the Society for Vascular Surgery and the American Venous Forum.7) These methods have several advantages, including decreased pain, less morbidity, shorter hospital stay, and faster return to work. More recently, Rasmussen et al. reported that RFA yielded results that were at least similar to those of EVLA. ${ }^{8)}$ Specifically, RFA was reported to be associated with significantly less post-procedural pain than EVLA. Though RFA is associated with fewer postoperative complications, ${ }^{4)}$ there is little evidence for RFA of advanced age patients. We presented that there were low 
postoperative complications in both young and elderly patients in Table 2. The results of our study shows that RFA for elderly patients is as safe and effective as for younger patients. After RFA, VCSSs of both groups decreased sufficiently in the present study.

In our study, there were more patients with ischemic heart disease and/or cerebrovascular disease in E-group (Table 2). Aging is an important factor of the causes for arteriosclerosis, ${ }^{9)}$ and is the reason for more patients having malignant tumor in E-group (Table 1). Though there was no significant difference in preoperative ejection fraction between groups, more patients with postoperative edema were in E-group than in Y-group. The reason for this is that valvular heart disease is more prevalent in elderly patients. However, there was no significant difference in patients with other minor postoperative complications between both groups, and so we showed that RFA was an adequate intervention for advanced age patients.

In this present study, only one limb of Y-group showed evidence of partial recanalization on follow-up (Table 2). This procedure demonstrated successful vein occlusion in $99.4 \%$ limbs. Encouraging occlusion rates of saphenous veins after RFA have been reported in several studies. Kapoor et al. presented patients with saphenous venous insufficiency seen $100 \%$ closure on doppler studies along with lesser complications. ${ }^{10)}$ Nordon et al. reported that vein occlusion was $97 \%$ for RFA after three months. ${ }^{11)}$ Proebstle et al. achieved an initial vein occlusion rate of $100 \%$ and $91.9 \%$ at 5 years. ${ }^{12)}$ Although dilation of vein diameter ${ }^{13)}$ and obesity ${ }^{14}$ ) were factors that affected postoperative recanalization, few authors suggested an association between aging and recanalization or recurrence. In our study, there was no recanalization in E-group, and so aging does not seem to be a factor of recanalization after RFA.

The rate of EHIT was reported to have a much lower incidence in RFA $(2.7 \%-3.4 \%) .{ }^{4,15)}$ According to previous studies, risk factors for EHIT include age. However, Sufian et al. reported that there was no relationship between EHIT and age by adopting EVLA, ${ }^{16)}$ and so it remains controversial whether age is a risk factor for EHIT. Additionally, few studies have reported a relationship between EHIT and age by performing RFA. We demonstrated that there were two limbs $(4.1 \%)$ in E-group and four limbs $(2.8 \%)$ in Y-group, and that there was no significant difference between both groups in incidence rate of EHIT (Table 2, $\mathrm{p}=0.665$ ). Aging may be not a risk factor of EHIT.

There was comparison of patients who underwent RFA with patients who underwent stripping of the saphenous veins in our study. However, elderly patients were only three, so we could not compare RFA and stripping adequately. However, there are many studies ${ }^{17)}$ that have demonstrated RFA is superior to stripping. Additionally, Sutzko et al. ${ }^{18)}$ presented that there was no significant difference in the improvement in CEAP and VCSS between patients younger and older than 65 years. Therefore, it may be concluded that RFA can be performed safely in the elderly compared to conventional treatment.

The results of this study had certain limitations. The present study is a retrospective study, and so the result was limited by the relatively small number of patients included because our study was a single-center experience. Despite these limitations, our study was able to show that RFA was a clinically useful procedure for elderly patients.

\section{Conclusion}

For elderly patients, RFA is a safe and effective strategy for varicose veins treatment of lower extremities. It might be considered clinically useful for a wide-range ages.

\section{Disclosure Statement}

There is no conflict of interest for this article.

\section{Author Contributions}

Study conception: KT, TM

Data collection: KT, SS

Analysis: KT

Investigation: KT

Writing: KT

Funding acquisition: none

Critical review and revision: all authors

Final approval of the article: all authors

Accountability for all aspects of the work: all authors

\section{References}

1) Satokawa $H$, Yamaki $T$, Iwata $H$, et al. Treatment of primary varicose veins in Japan: Japanese Vein Study XVII. Ann Vasc Dis 2016; 9: 180-7.

2) Shiraishi Y, Yamaki T, Mo M, et al. Venous leg ulcer in Japan: Japanese Vein Survey XIX. Japanese Journal of Phlebology 2018; 29: 1-12. (in Japanese)

3) The Survey Committee of the Japanese Society of Phlebology; Iwata H, Satokawa H, Sakata M, et al. the Japanese Vein Study: the 12th Survey of Varicose Veins. Japanese Journal of Phlebology 2013; 24: 432-9. (in Japanese)

4) Tamura K, Maruyama T. Mid-term report on the safety and effectiveness of endovenous radiofrequency ablation for varicose veins. Ann Vasc Dis 2017; 10: 398-401.

5) Tamura K, Nakahara H. MR venography for the assessment of deep vein thrombosis in lower extremities with varicose veins. Ann Vasc Dis 2014; 7: 399-403.

6) Kabnick LS, Ombrellino M, Agis H, et al. Endovenous heat induced thrombosis (EHIT) at the superficial deep venous 
junction: a new post-treatment clinical entity, classification and potential treatment strategies. In: Proceedings of the 18th Annual Meeting of the American Venous Forum; 2006; Miami, FL. Miami; 2006.

7) Gloviczki P, Comerota AJ, Dalsing MC, et al.; Society for Vascular Surgery, American Venous Forum. The care of patients with varicose veins and associated chronic venous diseases: clinical practice guidelines of the Society for Vascular Surgery and the American Venous Forum. J Vasc Surg 2011; 53 Suppl: 2S-48S.

8) Rasmussen LH, Lawaetz M, Bjoern L, et al. Randomized clinical trial comparing endovenous laser ablation, radiofrequency ablation, foam sclerotherapy and surgical stripping for great saphenous varicose veins. Br J Surg 2011; 98: 107987.

9) Tanaka H, Date C, Chen H, et al. Research activities of epidemiology in Japan. Cardiovascular disease. A brief review of epidemiological studies on ischemic heart disease in Japan. J Epidemiol 1996; 6 Suppl: S49-59.

10) Kapoor A, Kapoor A, Mahajan G. Endovenous ablation of saphenofemoral insufficiency: analysis of 100 patients using RF closure fast technique. Indian J Surg 2010; 72: 458-62.

11) Nordon IM, Hinchliffe RJ, Brar R, et al. A prospective double-blind randomized controlled trial of radiofrequency versus laser treatment of the great saphenous vein in patients with varicose veins. Ann Surg 2011; 254: 876-81.
12) Proebstle TM, Alm BJ, Göckeritz O, et al. Five-year results from the prospective European multicentre cohort study on radiofrequency segmental thermal ablation for incompetent great saphenous veins. Br J Surg 2015; 102: 212-8.

13) Calcagno D, Rossi JA, Ha C. Effect of saphenous vein diameter on closure rate with ClosureFAST radiofrequency catheter. Vasc Endovascular Surg 2009; 43: 567-70.

14) Bunnell AP, Zaidi S, Eidson JL 3rd, et al. Factors associated with saphenous vein recanalization after endothermal ablation. Ann Vasc Surg 2015; 29: 322-7.

15) Kurihara N, Hirokawa M, Yamamoto T. Postoperative venous thromboembolism in patients undergoing endovenous laser and radiofrequency ablation of the saphenous vein. Ann Vasc Dis 2016; 9: 259-66.

16) Sufian S, Arnez A, Labropoulos N, et al. Endovenous heatinduced thrombosis after ablation with $1470 \mathrm{~nm}$ laser: incidence, progression, and risk factors. Phlebology 2015; 30 : 325-30.

17) Rasmussen LH, Lawaetz M, Bjoern L, et al. Randomized clinical trial comparing endovenous laser ablation, radiofrequency ablation, foam sclerotherapy and surgical stripping for great saphenous varicose veins. Br J Surg 2011; 98: 107987.

18) Sutzko DC, Andraska EA, Obi AT, et al. Age is not a barrier to good outcomes after varicose vein procedures. J Vasc Surg Venous Lymphat Disord 2017; 5: 647-57.e1. 